\title{
DILEMAS, DIFICULDADES E POSSIBILIDADES DA ATUAÇÃO DOS GERENTES INTERMEDIÁRIOS COMO MEDIADORES DAS RELAÇÕES DE TRABALHO NO ATUAL CONTEXTO
}

Dissertação apresentada como requisito parcial para obtenção do título de Mestre pelo Programa de Pós-Graduação em Administração de Empresas da PUC-Rio.

Orientador: Jose Roberto Gomes da Silva

Rio de Janeiro dezembro de 2008 
Solange de Lima Freiria

Dilemas, Dificuldades e Possibilidades da Atuação dos Gerentes Intermediários como mediadores das Relações de Trabalho no Atual Contexto

Dissertação apresentada como requisito parcial para obtenção do grau de Mestre pelo Programa de Pósgraduação em Administração de Empresas da PUCRio. Aprovado pela Comissão Examinadora abaixo assinada.

Prof. Jose Roberto Gomes da Silva

Orientador

Departamento de Administração - PUC-Rio

Profa. Sandra Regina Santos Souza

Departamento de Informática - PUC-Rio

Profa. Úrsula Wetzel

COPPEAD- UFRJ

Prof. Nizar Messari

Vice-Decano de Pós-Graduação do CCS

Rio de Janeiro, 18 de dezembro de 2008 
Todos os direitos reservados. É proibida a reprodução total ou parcial do trabalho sem autorização da universidade, da autora e do orientador.

\section{Solange de Lima Freiria}

Graduou-se em Administração de Empresas na Fundação de Ensino Eurípedes Soares da Rocha (Marília-SP) em 1994. Cursou Especialização em Qualidade Total e Desenvolvimento Gerencial na FAFI (Faculdade de Filosofia de Cornélio Procópio - PR) em 1996. E em 2005 cursou MBA em Maganement no IAG/PUC-Rio.

Atua como supervisora da seção acadêmica e assessora da CCE/PUC-Rio desde 1998.

Ficha Catalográfica

Freiria, Solange de Lima

Dilemas, dificuldades e possibilidades da atuação dos gerentes intermediários como mediadores das relações de trabalho no atual contexto / Solange de Lima Freiria; orientador: José Roberto Gomes da Silva. - Rio de Janeiro: PUC, Departamento de Administração, 2008.

$100 \mathrm{f.} \mathrm{;} 30 \mathrm{~cm}$

Dissertação (mestrado) - Pontifícia Universidade Católica do Rio de Janeiro, Departamento de Administração.

Inclui bibliografia

1. Administração - Teses. 2. Contrato Psicológico. 3. Gerente Intermediário. 4. Relações de Trabalho. I Silva, José Roberto Gomes da. II. Pontifícia Universidade Católica do Rio de Janeiro. Departamento de Administração. III. Título. 


\section{Agradecimentos}

Muitas são as pessoas presentes em nosso dia a dia, renovando continuamente nossas esperanças. Algumas destas pessoas são especiais, outras, por motivos justificados, são mais especiais do que todas. Porém todas ao seu modo devem merecer sempre o nosso respeito, carinho e consideração.

Portanto quero expressar meus agradecimentos àqueles que, com seu modo especial, estiveram ao meu lado nesta caminhada.

Primeiramente a DEUS, por SEMPRE estar ao meu lado, impondo desafios que me fortalecem a cada dia.

Ao meu amado Alvismar, companheiro e amigo que soube entender a importância dessa etapa da minha vida, dando o apoio necessário ao longo desses anos. Nas muitas noites e fins de semana sacrificados em prol dos estudos, soube compreender, suportando meu mau humor e cansaço.

Às minhas filhotas, Judy, Cinthy, Meg (in memóriam), Deby, que nos dias e noites dedicadas à este trabalho, sempre estiveram ao meu lado ou em cima dos meus textos. Todas ao seu modo serviram como escape, ora como ouvintes silenciosas, ora como distração com suas encantadoras estripulias. E também à Jolye, novo membro da família, que não participou da confecção do trabalho, mas foi companheira inseparável durante a formatação da versão final.

Aos meus pais, Luzia e Baptista, que com muito esforço, carinho e dedicação, conseguiram fazer de mim uma pessoa de fibra. E hoje, orgulhosos, podem presenciar mais uma conquista.

Aos meus irmãos, sobrinhos e demais familiares, que mesmo distantes estiveram sempre presentes, acreditando e dando força.

Ao professor Augusto Sampaio, Vice-Reitor Comunitário, que com seu apoio e sua confiança, tornou possível mais esta conquista. 
Ao professor e orientador José Roberto Gomes da Silva, por sua paciência ao tentar driblar a minha economia de palavras e a minha ansiedade. E principalmente, por sua dedicação, e profissionalismo transformando esse trabalho em uma verdadeira dissertação.

A todos os demais professores pela dedicação e paciência com que conduziram suas aulas durante este longo período, nos incentivando a construir o conhecimento e nos oferecendo o que tinham de melhor.

A todos os gestores e empresas, que se prontificaram a participar deste trabalho, acreditando e fornecendo todo o material necessário, imprescindível para a consecução deste trabalho.

À minha querida e dedicada equipe de trabalho, que foram os principais motivadores para a escolha desse tema. Que com o profissionalismo e carinho de suas ações, me impulsionam a buscar formas de me tornar um líder e não apenas um chefe.

Aos demais colegas e amigos da CCE, que me deram apoio ouvindo as minhas reclamações e festejando comigo a todas as conquistas.

Aos colegas de classe por termos juntos vencidos todas as batalhas.

A todos os amigos cujos nomes aqui não se encontram declarados, mas que, de um modo especial, colaboraram para a consecução desta pesquisa e que merecem meu respeito, carinho e consideração.

À Tereza, Fábio e todos os funcionários administrativos do departamento de administração (IAG), pela dedicação e carinho que trabalharam para que tivéssemos o melhor.

Por fim, a todos que diretamente e indiretamente contribuíram para realização desta pesquisa. 


\section{Resumo}

Freiria, Solange de Lima; da Silva; José Roberto Gomes (Orientador), Dilemas, dificuldades e possibilidades da atuação dos gerentes intermediários como mediadores das relações de trabalho no atual contexto. Rio de Janeiro, 2008. 100p. Dissertação de Mestrado (Opção Profissional) - Departamento de Administração, Pontifícia Universidade Católica do Rio de Janeiro.

O ambiente organizacional esta sofrendo mutações constantes, seja pelo avanço tecnológico, pela globalização ou pelo aumento da concorrência que está cada vez mais agressiva. Para se manterem competitivas as empresas são obrigadas a se tornar mais flexíveis e versáteis e isso significa mudança não somente em seus procedimentos, mas principalmente no que se refere ao gerenciamento de pessoas, pois o capital humano é considerado um diferencial dificilmente copiável. O objetivo deste estudo foi apresentar as dificuldades enfrentadas pelos gerentes dos níveis intermediários em seu papel como mediadores das relações de trabalhos e mais especificamente do contrato psicológico de seus subordinados. Para isso, esta dissertação aborda quatro grandes temas como: liderança no atual contexto, as mudanças nas relações de trabalho, desafios gerenciais e contrato psicológico. De maneira a tentar compreender estas mudanças e os dilemas gerenciais, foram realizadas entrevistas semi-estruturadas com 21 gerentes intermediários de empresas públicas e privadas de diferentes portes e setores. Os gerentes entrevistados possuem várias atribuições, dentre elas a de serem mediadores nas relações de trabalho entre os subordinados e as empresas. O resultado das entrevistas evidenciou que as mudanças sofridas nas organizações provocaram alterações significativas no perfil gerencial e nas relações de trabalho. Verificou-se que o gerente médio além de ser um influenciador, se tornou mais sensível e mais próximo dos seus dirigidos e dirigentes, possibilitando com isso a identificação e tratamento das expectativas envolvidas na relação de trabalho, com o intuito de conseguir um equilíbrio entre as partes.

\section{Palavras-Chave}

Contrato Psicológico, Gerente Intermediário, Relações de Trabalho. 


\section{Abstract}

Freiria, Solange de Lima; da Silva; José Roberto Gomes (Advisor), "Dilemmas, Difficulties and possibilities of middle management performance as mediators of labor relations in the present context". Rio de Janeiro, 2008. 100p. MSc. Dissertation (Opção Profissional) Departamento de Administração, Pontifícia Universidade Católica do Rio de Janeiro.

The organizational environment this suffering constant mutations, either for the technological advance, the globalisms or the increase of the competition that is each more aggressive time. To remain competitive the companies they are obliged if to become more flexible and versatile and this not only means change in its procedures, but mainly as for the management of people, therefore the human capital is considered a hardly copied. The objective of this study was more specifically to present the difficulties faced for the middle manager levels in its paper as mediating of the labor relations and of the psychological contract of its subordinate. For this, this dissertation approaches four great subjects as: leadership in the current context, the management changes in the labor relations, challenges and psychological contract. In way to try to understand these changes and the management dilemmas, had been carried through interviews half-structuralized with 21 middle managers of public companies and private of different transports and sectors. The interviewed managers possess some attributions, amongst them to be mediating in the labor relations between the subordinate and the companies. The result of the interviews evidenced that the changes suffered in the organizations had provoked significant alterations in the management profile and the labor relations. It was verified that the average manager beyond being a influential, if it became more sensible and next to directed and leading its, making possible with this the identification and treatment of the involved expectations in the labor relations, with intention to obtain a balance between the parts.

\section{Keywords}

Psychological Contract; Middle Manager; Labor Relations 


\section{Sumário}

DESCRIÇÃO DO PROBLEMA

1.1. Introdução 11

1.2. Objetivos da Pesquisa $\quad 15$

1.3. Relevância do Estudo 15

$\begin{array}{ll}\text { 1.4. Delimitação do Estudo } & 17\end{array}$

2. REFERENCIAL TEÓRICO 19

2.1. Organizações Contemporâneas Modelando o Novo Perfil de Pessoal 19

2.2. Liderança de Equipe no Atual Contexto 24

2.3. Papel do Gerente Médio $\quad 27$

2.4. Relações de Trabalho 32

2.5. Desafios Gerenciais 36

2.6. Contrato Psicológico 43

3 METODOLOGIA 51

3.1. Tipo de Pesquisa $\quad 51$

3.2. Seleção dos Sujeitos

3.3. Coleta de Dados 56

3.4. Tratamento dos Dados 58

3.5. Limitações do Método 59

4. RESULTADOS 61

4.1. A visão sobre a liderança 61

4.2. A visão sobre as relações de trabalho e o papel do gerente 67

4.3. A visão sobre os desafios gerenciais $\quad 72$

4.4. A visão sobre o contrato psicológico $\quad 80$

5 CONCLUSÕES E SUGESTÕES 90

$\begin{array}{ll}5.1 \text { Conclusão } & 90\end{array}$

5.2 Sugestão para Pesquisas Futuras 95

6 REFERÊNCIAS BIBLIOGRÁFICAS 96 


\section{Lista de quadros}

Quadro 1 Caracterização dos Entrevistados 54

Quadro 2 Questões Aplicadas separadas por Tópicos 58

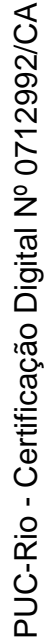


"Não é o mais forte nem o mais inteligente que sobrevive. É o mais adaptado às mudanças"

(Charles Darwin) 